\title{
Optimization of Composite Process Parameters on Fracture Toughness of Glass Fiber Reinforced Plastics
}

\author{
H. Muralidhara, R. Suresh, M. Krishna
}

\begin{abstract}
The objective of the work was to investigate statistical analysis of fracture toughness of the glass fiber reinforced composites at different stacking sequences, strain rate and crack length. The glass reinforced Vinylester composites prepared by hand lay-up technique with various stacking sequences such as 0/90, 45/-45 and chopped strand orientations. 3-point bending for fracture toughness test for various notch depth ratio's as per linear elastic fracture mechanics concept was conducted. Further the initial notch depth method was adopted to find the critical stress intensity factor KIC for the given notch depth ratio. Design of experiment using the Taguchi L9 array was formulated to understand the influence of parameters on fracture toughness. ANOVA was performed to find out the influencing weightage factor for fracture toughness. Regression analysis was used to develop a mathematical model that gave the contribution of individual parameters on responses. The fracture surface was investigated using scanning electron microscopy (SEM).The DOE response surface methodology showed the stacking sequence of [45/-45/0/90/Chopped]3s, with strain rate of $0.5 \mathrm{~mm} / \mathrm{min}$ and without notch having the highest fracture toughness of 81.36 Mpa . ANOVA was carried out to know the statistical significance of factors influencing fracture toughness, Results showed that notch depth ratio was the most influencing factor with $68.67 \%$ and stacking sequence with $24 \%$. Accuracy of developed regression model was $90.61 \%$ (R2), which indicating the confidence level of regression.
\end{abstract}

Keywords--- Fracture Toughness, Composite Process Parameters.

\section{INTRODUCTION}

Composite materials having the advantage of higher strength to weight ratio, resistance to corrosion, acids and to impact loads are replacing the metal alloys in spacecraft and automobile industries. The increase in use of composite materials in many engineering application like aerospace, ship building, etc has motivated researchers to understand their behavior with various types of loading. One of the areas of interest is to understand the resistance of composite to fatigue crack formation and propagation [1,2]. at this stage, determination of stress intensity factor becomes important. Fracture toughness is a fracture mechanics parameter that measures the load carrying ability of precracked component [3-5]. Fatigue failure is the degradation of the mechanical properties of a component due to the repeated load. It is understood from the past experience that the component will fail even if the stress acting on it is well below the yield strength of the material [6]. Fracture mechanics is based on the assumption that there exists a

\footnotetext{
Manuscript received September 16, 2019.

H. Muralidhara, Managing Director, Indval Technologies Pvt Ltd, Bangalore, India. (e-mail: hmuralidhara@gmail.com)

R. Suresh, Professor, Dept. of Mechanical Engineering, VTU P.G Studies, Mysuru, India. (e-mail: drsureshvtu@gmail.com)

M. Krishna, Professor, Dept. of Mechanical Engineering, RV Engineering College, Bangalore, India. (e-mail: krishnam@rvce.edu.in)
}

crack in the structural component in the form of a man made hole, a notch, a slot, a re-entrant corner or it can be due to manufacturing defects like slag inclusion, crack in a weldment or heat affected-zones due to uneven cooling, presence of foreign particles etc [7]. Fatigue is the cause of crack and final fracture in a mechanical component, it is important to assess the performance of composite structures under the basis of s-n data [8,9].for composite materials multiple transverse cracks may initiate at free edges and subsequently moves into the laminate which will degrade the stiffness while providing the site for de-lamination [10]. Hence damage tolerance design concepts in high end applications like aerospace and shipbuilding is gaining more importance and study related to crack propagation and fracture of components have gained more focus in the recent years. In the literature, the effect of glass fiber reinforced in matrix containing ceramic particles was studied and effect of varying notch depth, the volume fraction of fiber and resin content were also studied [11-15]. Many research works related to effect of fiber/matrix volume fraction, fiber orientation and notch depth ratio on kic have been reported in the past. By taking one variable parameter at a time the fracture behavior was studied but effect of all the three parameters and interaction between them was not studied and was a concern. In this context, the present work was focused on finding the fracture toughness of fiber reinforced composite for variable test parameters under combined experimental and statistical analysis tool using Taguchi $\mathrm{L}_{9}$ array of design..

\section{EXPERIMENTAL STUDY}

The materials used in the present research were Vinylester, E-glass fiber laminas of 0/90, 45/-45, chopped strand orientations and additives: promoter, accelerator and catalyst were procured from reliable suppliers. Vinylesters are preferred in marine and civil applications due to their lower moisture absorption and mechanical property degradations than other resins such as epoxy, polyester, isopolyester. Vinylesters is particularly recommended for use in marine applications. Glass fibers are the most widely used reinforcement in FRP due to their availability and low price and hence used for the present study. E-Glass is the standard form of glass fiber and is also known as electrical grade glass fiber. The materials used are $\mathrm{E}$ glass fiber lamina, Vinylester resin, accelerator (Cobalt), Promoter (Di Methyl Acetamide), Catalyst (methyl Ethyl ketone peroxide), Mylar 


\section{OPTIMIZATION OF COMPOSITE PROCESS PARAMETERS ON FRACTURE TOUGHNESS OF GLASS FIBER REINFORCED PLASTICS}

sheet and Bosch cutter machine. Laminates were prepared by wet hand layup technique. Glass fibers were cut into 250 $\mathrm{mm}$ X $250 \mathrm{~mm}$ dimensions using a cutter and kept ready for laminate preparation. Molds were prepared with Mylar sheet attached to it by using an adhesive. The calculated amount of Vinylester resin was taken in a beaker and mixed with calculated amount of accelerator, promoter and catalyst and stirred properly to mix homogeneously.The prepared laminates were kept for curing under hot press for 24 hours at room temperature. The laminates removed from hot press were cut into required specimen size as per ASTM E399 three point bending fracture test standards.

Statistical Design of Experiments (DOE) consists of variation of several parameters at a time when compared to one factor at a time approach where only one factor varied keeping all other factors constant which is tedious. Douglas [5] reported that DOE can be used to find the relationship and interaction between variables that affect the results so that considerable amount of time and material is saved. DOE was applied using statistical software MINITAB V16.

$$
\begin{gathered}
K_{s c}=\left(P_{Q} S\right) /\left(B W^{3 / 2}\right) f(a / W) \\
f(a / W)=\frac{3 \sqrt{a / W}}{2\left(1+2 \frac{a}{W}\right)\left(1-\frac{a}{W}\right)^{3 / 2}}\left[1.99-\frac{a}{W}\left(1-\frac{a}{W}\right)\left(2.15-3.93 \frac{a}{W}+2.7\left(\frac{a}{W}\right)^{2}\right)\right]
\end{gathered}
$$

Fracture toughness was determined using initial notch depth formula as given Table 1 .

Table 1: Factors and their corresponding variability levels

\begin{tabular}{llll}
\hline Factors & Level 1 & Level 2 & Level 3 \\
\hline Stacking & {$[0 / 90 / 45-$} & {$[$ Chopped/45/- } & {$[45 /-$} \\
sequence & $45 /$ chopped $]_{6 \mathrm{~s}}$ & $45 / 0 / 90]_{6 \mathrm{~s}}[2]$ & $45 / 0 / 90 /$ Chopped $]_{6 \mathrm{~s}}$ \\
& {$[1]$} & & {$[3]$} \\
Strain rate & 0.5 & 1.5 & 2.5 \\
Notch & Without notch & 0.38 & 0.5 \\
depth ratio & {$[0]$} & & \\
\hline
\end{tabular}

The number of experiments required analyzing the factors affecting the fracture toughness by full factorial design of 3 levels and 3 factors are 27. In practical scenario, it is tedious and hence for this reason, orthogonal array method which provides techniques to analyse the factors with minimal number of experiments. Using $\mathrm{L}_{9}$ array with factors stacking sequence, strain rate and notch

Three trials were done for each experiment and mean value is chosen as the fracture toughness. ANOVA was performed to investigate the influence of parameters on the response fracture toughness and found that notch depth ratio was the highly influencing factor on fracture toughness.

\section{RESULTS AND DISCUSSION}

Normal probability plot for Fracture toughness is as shown in Fig 2. The $\mathrm{SN}$ ratios for the experimental response are found to be within the tolerance of $5 \%$ and equally distributed along the trend line of normal probability plot. Hence the process is said to be stable

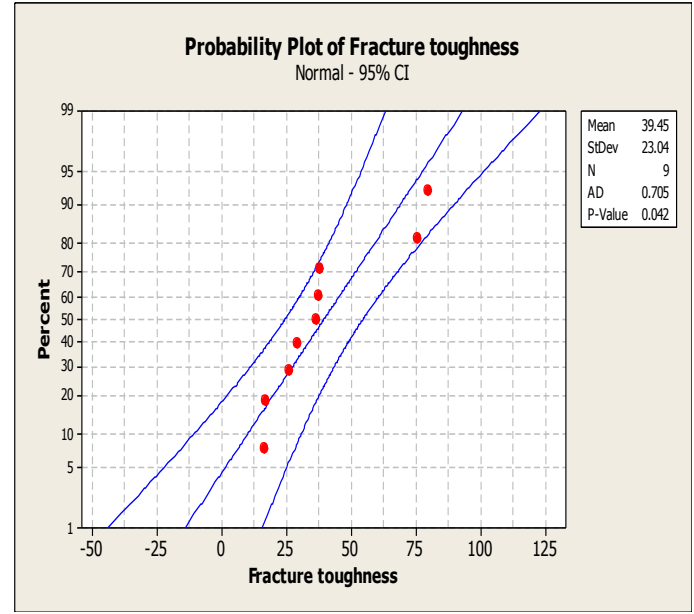

Fig. 2: Probability plot for fracture toughness

\section{MAIN DEFECTS PLOT FOR FRACTURE TOUGHNESS}

From the main effect plot for fracture toughness shown in Fig 3. It is observed that individually with the increase in strain rate, from $0.5 \mathrm{~mm} / \mathrm{min}$ to $2.5 \mathrm{~mm} / \mathrm{min}$ fracture toughness increased by $30 \%$, and with the increase in notch depth ratio from 0 to 0.5 the fracture toughness decreased by $62 \%$.

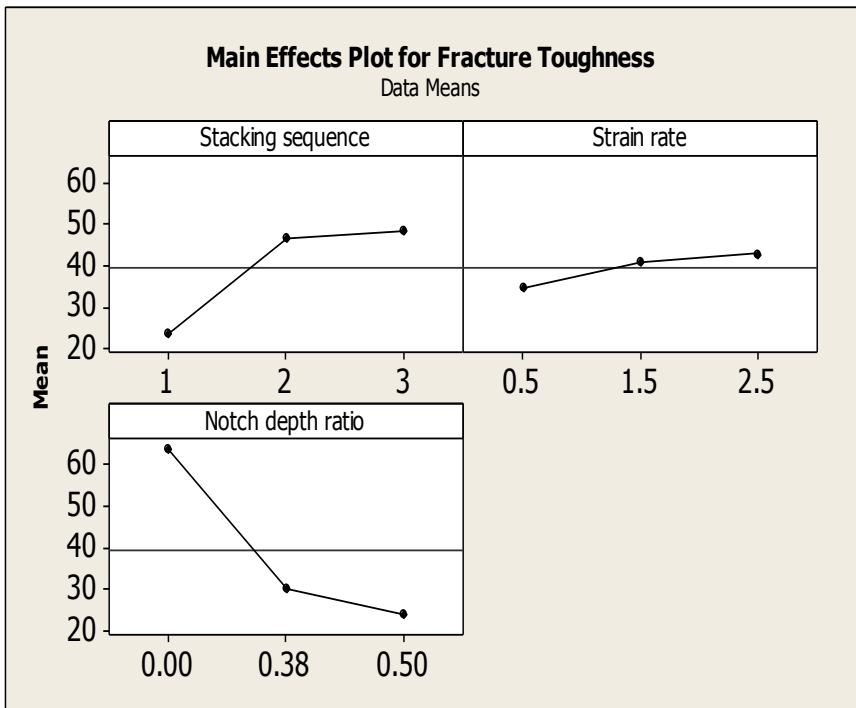

Fig. 3: Main effect plot for fracture toughness

Fracture toughness is highest for the stacking sequence (3) $[45 /-45 / 0 / 90 / \text { Chopped }]_{6 s}$ with the symmetric arrangement of 6 plies.

Regression analysis showed the relation between different factors affecting the fracture toughness which is given by

Fracture toughness $=32.7546+12.4383$ stacking sequences +3.99167 strain rate -82.401 notch depth ratio

Where it is evident that the contribution of notch depth ratio is high at 82.01 in decreasing the fracture toughness and contribution other parameters in increasing the value of $\mathrm{K}_{\mathrm{IC}}$ is very minimal at 12.43 and 3.99 . 

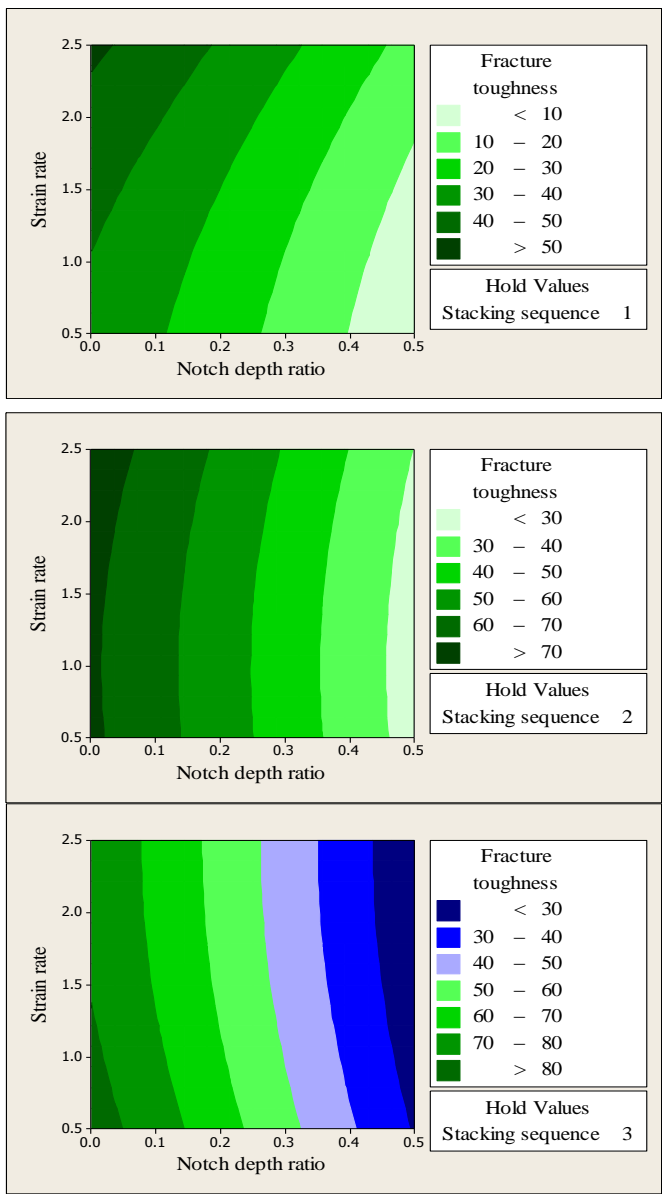

Fig. 4: Contour plot of fracture toughness vs strain rate, notch depth ratio by holding stacking sequence at 1,2 and 3

\section{V.RESPONSE SURFACE METHODOLOGY}

Contour plots of responses are plotted keeping one parameter fixed and varying other two and are as shown below.

Contour plot obtained for a given stacking sequence of 1 , 2, 3 shown in Fig 4. It is evident that Fracture toughness of the composite plate with plain 0/90 laminate has highest among 0/90, 45/-45 and chopped strand glass fiber. By stacking them in the order [213] we can achieve higher fracture toughness more than $80 \mathrm{MPa} \sqrt{m}$ which is visualized from the plots.

Contour plots for the fixed values of strain rates 0.5 and $2.5 \mathrm{~mm} / \mathrm{min}$, shown in Fig 5. It is inferred that strain rate has a better effect on the fracture toughness, with the increase in strain rate the fracture toughness increases indicating that materials become stiffer increasing its ability to resist fracture. High loading rates will make the material more brittle resulting in reduced ability to plastic deformation and thus lower the fracture toughness. Thus loading is one of the important parameters to be observed during fracture tests.

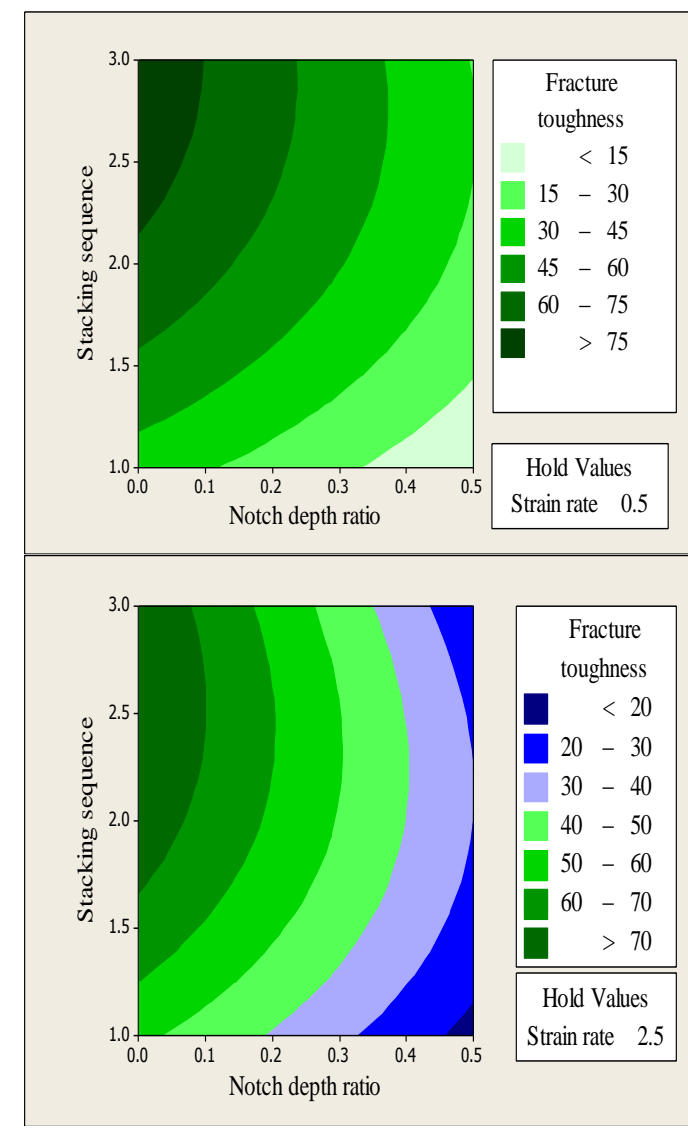

Fig. 5 Contour plot of fracture toughness v/sstacking sequence, notch depth ratio by holding strain rate at 0.5 and 2.5

Contour plot obtained for a fixed value of notch depth ratios of 0 , and 0.5 . It is observed that the fracture toughness of the composite material decreases with increase in the notch depth ratio as shown in Fig. 6 and it is highest for the stacking sequence of $[45 /-45 / 0 / 90 / \text { chopped }]_{6 s}$ with strain rate 1.45 .

\section{RESPONSE SURFACE OPTIMIZATION PARAMETERS}

The response surface optimization parameters are as shown in Fig 7. The optimized parameters responsible to increase the fracture toughness are Stacking sequence [45/$45 / 0 / 90 /$ chopped $]_{6 s}$, strain rate $0.5 \mathrm{~mm} / \mathrm{min}$, with notch depth ratio $(\mathrm{a} / \mathrm{b}) 0$ which gives the maximun fracture toughness of 84.8733 MPa $\sqrt{m}$.The response surface optimizer gives the parameters highly influencial in decreasing fracture toughness as stacking sequence [0/90/45-45/chopped] $]_{6 \mathrm{~s}}$ with strain rate $0.5 \mathrm{~mm} / \mathrm{min}$ and notch depth ratio $(\mathrm{a} / \mathrm{b}) 0.5$ with 1.8002 as fracture toughness $\mathrm{MPa} \sqrt{m}$. 


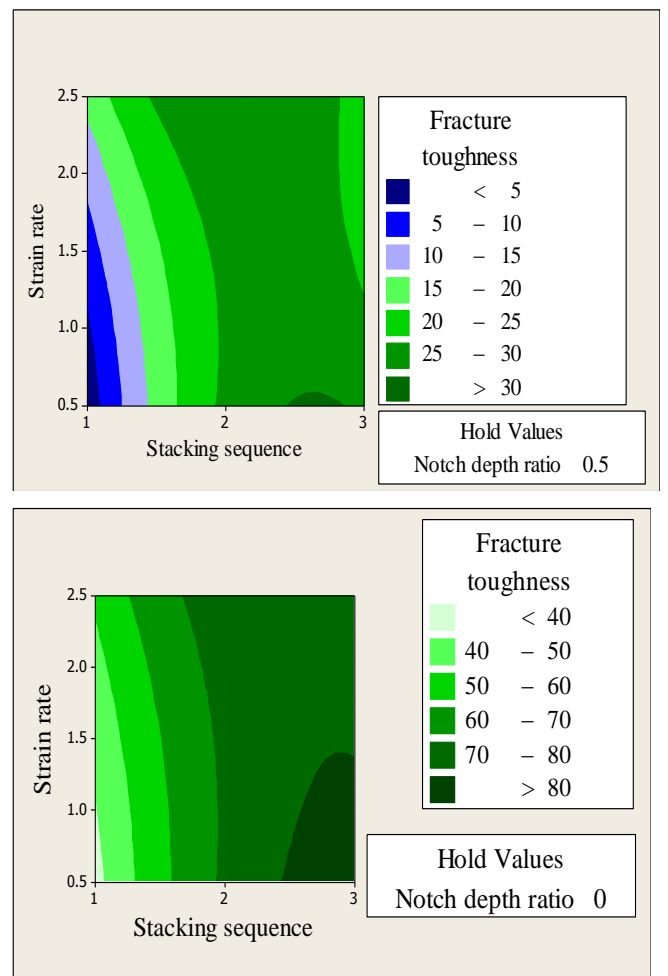

Fig. 6: Contour plot of fracture toughness vs strain rate, stacking sequence by holding notch depth ratio at 0 and 0.5

\section{CONCLUSIONS}

The fracture toughness KIC of composite plates with woven glass fibers of different orientations were calculated experimentally and the conclusions may be listed as:

- Fracture toughness of composite plates, KIC, is calculated for an edge crack and the effect of variation of fiber reinforcement angle on fracture toughness is determined. Fracture toughness decreases in the order of $0 / 90$ to chopped and then to $45 /-45$.

- But by stacking these woven fibers in different orders we get the one with [45/-45/0/90/chopped]6s order as highest KIC, then with order [chopped/45/$45 / 0 / 90] 6 \mathrm{~s}$ and the lowest with [0/90/45/45/chopped]6s.

- The maximum fracture toughness obtained was $79.53 \mathrm{MPa} \sqrt{m}$ for stacking sequence [45/45/0/90/chopped]6s strain rate 1.5 and the notch depth ratio 0 .

- By conducting statistical analysis KIC highest is obtained was $84.8733 \mathrm{MPa} \sqrt{m}$ for laminate [45/$45 / 0 / 90 /$ chopped]6s with strain rate 0.5 and without notches.

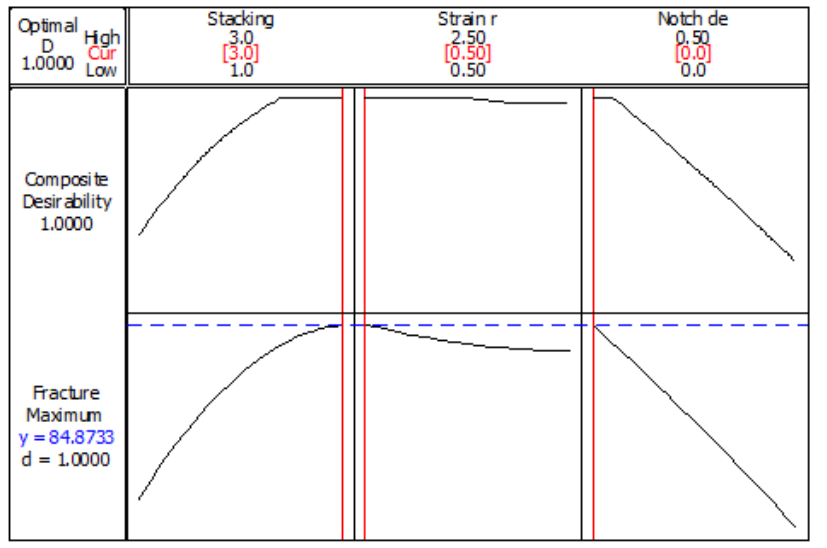

Fig.7: Response surface optimization plot

\section{REFERENCES}

1. Christian Carloni, Kolluru V. Subramaniam Investigation of sub-critical fatigue crack growth in $\mathrm{FRP} /$ concrete cohesive interface using digital image analysis Composites: Part B 51 (2013) 35-43

2. M.E Waddoups, J.R. Eisenmann, B.E. Kaminski. Macroscopic Fracture Mechanics of Advanced Composite Materials. Journal of Composite Materials June1, 2010 44: 1335-1349.

3. E. E. Gdoutos, Fracture Mechanics: An Introduction, 2nd ed., Springer, Norwell, MA, 2005.

4. K. Friedrich, Application of Fracture Mechanics to Composite Materials, vol. 6, Elsevier Science, New York, 1989, 1989

5. C. Navarro, J. Vazquez, J. Dominguez. 3D vs. 2D fatigue crack initiation and propagation in notched plates. International Journal of Fatigue 58 (2014) 40-46

6. Prashant Kumar. Elements of Fracture Mechanics Wheeler Publishing.

7. Kassapoglou C. Fatigue model for composites based on the cycle-by-cycle probability of failure: implications and applications. J Compos Mater 2011;45(3):261-77

8. Philippidis TP, Passipoularidis VA. Residual strength after fatigue in composites: theory versus experiment. Int J Fatigue 2007:29(12):2014-16

9. Greenhalgh E, Garcia MH. Fracture mechanisms and failure processes at stiffener run-outs in polymer matrix composite stiffened elements. Composites: Part A 2004;35:1447-58.

10. A. Avci, H. Arikanb, A. Akdemir. Fracture behavior of glass fiber reinforced polymer composite. Cement and Concrete Research 34 (2004) 429-434

11. N. Tarakcioglu, A. Akdemir, A. Avci, Strength of filament wound GRP pipes with surface crack, Composites B 32 (2001) 131- 138.

12. J.R. Rice, A path independent integral and the approximate analysis of strain concentration by notches and cracks, J. Appl. Mech. Trans. 35 (1968) 379- 386.

13. Tan SC, Stress concentrations in laminated composites. Boca Raton, Florida (USA): CRC Press/Tylor and Francis Group:1994.

14. D.J. Wilkins et al.Characterizing delamination growth in graphite-epoxy ASTM STP 775, American Society for Testing and Materials, Philadelphia (1982), pp. 168-183

15. L.E. Asp, A. Sjögren, E.S. Greenhalgh Delamination growth and thresholds in a carbon/epoxy composite under fatigue loadingJ Compos Technol Res, 23 (2) (2001), pp. 55-68. 